\title{
Complaints arising from a mismatch between school furniture and anthropometric measurements of rural secondary school children during classwork
}

\author{
Prakash Chandra Dhara · Gurucharan Khaspuri · \\ Soudeep Kumar Sau
}

Received: 23 December 2006/Accepted: 29 September 2008/Published online: 13 November 2008

(C) The Japanese Society for Hygiene 2008

\begin{abstract}
Objectives The present investigation aimed to evaluate the extent of mismatch between different dimensions of school furniture and the respective anthropometric measures of school children. Assessment of health problems as well as postural pattern among the school children while attending their classes in relation to the classroom furniture was the other aim of this study.

Methods For this purpose, 621 male school children (age range 10-15 years) were selected at random from rural secondary schools $(n=20)$ in nine districts in the state of West Bengal, India. The subjective evaluation of health problems of the school children was made by questionnaire technique. Postural analysis of the children during classwork was made by video-photographic method as well as direct observation method. Anthropometric measures of the school children were taken by an anthropometer.

Results School children suffered from various discomforts/problems during classwork because of the school furniture. Anthropometric dimensions of the school children were found to increase with age, but most of the dimensions of the school furniture in different grades ( $\mathrm{V}$ to $\mathrm{X})$ remained more or less the same. The school children were found to change postures frequently while using such classroom furniture.

Conclusions Mismatches between the dimensions of school furniture and body dimensions might be the reason for the occurrence of discomfort/problems in various
\end{abstract}

P. C. Dhara $(\varangle) \cdot$ G. Khaspuri · S. K. Sau Ergonomics and Sports Physiology Division, Department of Human Physiology with Community Health, Vidyasagar University, Midnapore 721102, West Bengal, India e-mail: prakashdhara@rediffmail.com parts of school children's bodies. It can be concluded that an ergonomic intervention is required to redesign the classroom furniture for school children of different age groups in order to reduce furniture-related health complaints.

Keywords School furniture - Body dimensions . Health problems $\cdot$ Posture change

\section{Introduction}

The children of secondary school spend a considerable part of their daily life (about $5 \mathrm{~h}$ /day) in school. They spend about $80 \%$ of the school time in the classroom performing various activities, such as reading, writing, drawing, and other related activities, which require them to sit continuously for long hours [1]. It is most important that dimensions of the school classroom furniture (benches and desks) are suitable for the student. However, in most of the schools, the furniture is designed by the manufacturer without considering the anthropometric dimensions of the users (school children) of different age groups. As an outcome, benches and desks become unsuitable for the school children, compelling them to adopt awkward postures while attending their classes. Flaws in the furniture used by the students contribute to discomfort and inconvenience, adversely affecting classroom learning activity [2]. No comprehensive study has been done to identify furniture-related health problems among rural Bengalee (Indian) school children. In the present investigation, attempts have been made to assess anthropometric dimensions of the rural school children and the extent to which those dimensions mismatch with the physical dimensions of the school furniture. The problems rising 
because of this mismatch and the related postural change of the school children in the classroom have also been evaluated.

\section{Materials and methods}

\section{Selection of site}

The rural areas of West Bengal state (India) were the target areas of the present investigation. For conducting the present study, 20 rural secondary schools were selected at random from the randomly selected 9 districts out of 19 districts of West Bengal State (India).

\section{Selection of subjects}

A total of 621 school children between the ages of 10 and 15 years were chosen at random from the randomly selected 20 rural secondary schools. The school children were divided into six age groups [10 years $(n=106), 11$ years $(n=105), \quad 12$ years $\quad(n=104), 13$ years $(n=103)$, 14 years $(n=102)$, and 15 years $(n=101)]$. The children of different age groups belonged to different grades of the school (grade V: 10 years, grade VI: 11 years, grade VII: 12 years, grade VIII: 13 years, grade IX: 14 years, and grade $\mathrm{X}$ : 15 years). Each age group indicated a range of age (e.g., 10 years means 120-132 months and so on). Most of the school children in a grade belonged to their respective age groups. The school children of a grade who were not within the specified age group were excluded from the study.

The present study was approved by the Human Ethical Committee of the institution, and the experiment was performed in accordance with the ethical standards of the committee and with the Helsinki Declaration. All the school children volunteered for the present study. From all school children consents were taken according to the rules of the institution.

\section{Evaluation of health complaints}

Eighty (80) school children from each age group were selected (according to alphabetical order of their names) from the previously selected children. Subjective evaluation of discomfort/problems of the school children during/ after attending their class because of classroom furniture was evaluated by questionnaire technique. A questionnaire is presented in the Appendix. Before the interview the experimental protocol was explained to the school children individually. The privacy of the school children was maintained by writing codes (name code and school code) in the data sheet instead of putting their names directly. The coding was made by another experimenter.
Study of postural pattern of the school children

Twenty school children from each age group were selected (according to alphabetical order of their names) from the previously selected school children. The postural patterns of the selected school children in relation to the school furniture were studied while they attended classes by video photographic method [3]. The video camera (Handicam, Sony Corp., Japan), leveled on a tripod, was located approximately $2 \mathrm{~m}$ away from the school children and positioned perpendicular to the plane of motion. Postural changes of the boys were video recorded during classwork. The video records were then transferred to a computer, and the postural changes were analyzed after superimposing time onto it. Careful and repeated observations were made for minimizing errors. One student at a time was observed for one class period.

The major posture changes were observed by considering the changes of body joint angles (viz., joint angles of the neck, shoulder, elbow, hip, knee, and ankle) of the school children. The locations of the center of joints (both left and right joints) were marked by placing white stickers before taking the photograph. Stick diagrams were made for measuring the joint angles. Usually the segment of the angle proximal to the body was considered as reference. The following changes were noted: (1) neck lateral bend (right/left), (2) neck forward bend, (3) trunk bend (forward and backward), (4) trunk lateral bend (right/left), (5) leg (right and left) bends (flexion and extension at knee joint), and (6) cross leg condition. Judgment of the changes of joint angles when they were not able to be photographed from the perpendicular direction was made by direct observation method. In this case, body joint angles of the school children were measured by goniometric method [4] while the children attended classes. The center of the goniometer was adjusted over the estimated center of the joint, and the reference arms were aligned with the long axes of the adjoining body segments. The change of any joint angle more than 45 degrees was treated as a posture change. The frequency of posture change (i.e., number of changes of a particular posture) was computed for the total duration of a class period (40 min). The mean duration of each posture was also calculated. The duration of adopting each posture was also expressed in terms of percentage of the total duration of the class; the average value of 20 school children was given. Definitions of these joint angles are given below.

Neck flexion angle is the angle formed by both the line of the trunk and neck segment.

Shoulder joint angle is the angle between the vertical trunk (lateral) line and the upper arm at the acromial joint region.

Elbow joint angle is the angle between the upper arm and lower arm. 
Hip joint angle is the angle between the trunk and thigh. Knee joint angle is the angle between the thigh and lower leg.

Ankle joint angle is the angle between the lower leg and foot.

Evaluation of the design of school furniture

In the present investigation, a pair of a benches and a desk were considered as the classroom furniture. Traditionally, the school children sit on the bench and write on the desk. To get an idea of the shape and size of the classroom furniture, physical dimensions (shown in Fig. 1) of the same were measured. Physical dimensions of school furniture allotted for different grades (from grade $\mathrm{V}$ to grade $\mathrm{X}$ ) of the selected schools were measured by a steel measuring tape. The length of the bench was divided by the number of school children using it to get the per capita allotted length of the bench. In the same way per capita allotted desk length was also determined. The horizontal distance of the gap between the bench and the desk was taken as the clearance for standing. The horizontal distance was measured from the inner edge of the bench surface to the line of the inner edge of the desk surface.

Measurement of body dimensions

of the school children

Anthropometric measures of 621 school children were taken by adopting proper landmark definitions and standard

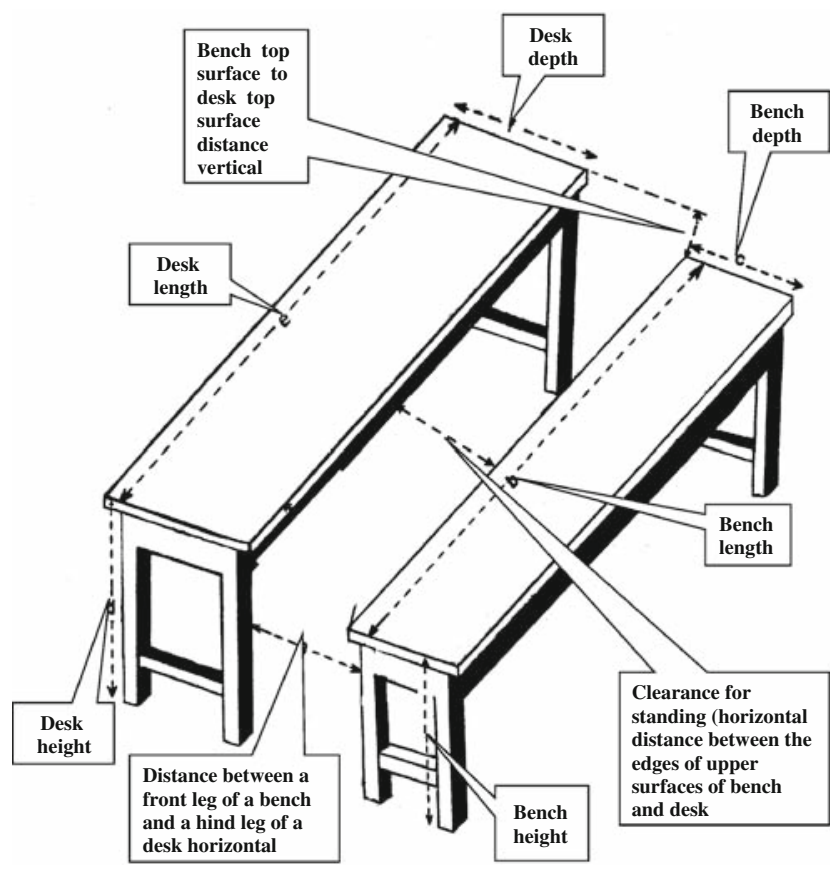

Fig. 1 Different dimensions of school furniture (these physical dimensions have been compared with the anthropometric dimensions of the school children) measuring techniques [5-8]. The equipment used for this purpose was an anthropometer (Holtain Ltd., UK). Accuracy and repeatability of measurement were achieved by practice prior to the data collection sessions. The data recorded for a subject were the mean of three trials. All the school children wore light clothes and were bare footed during the measurement. The anthropometric dimensions taken for this study were as follows:

Popliteal height. School children sat erect on a seat, feet on the adjustable platform; knees were flexed $90^{\circ}$ and the thighs parallel. The vertical distance from the floor to the lateral underside of the right thigh at a point contiguous to where the tendon of the biceps femoris muscle joins the lower leg was measured (Fig. 2a).

Buttock-popliteal length, sitting. School children were asked to sit erect on an adjustable seat with knees flexed at $90^{\circ}$ and thighs parallel. The horizontal distance from the most posterior aspect of the right buttock to the posterior surface of the right knee was measured (Fig. 2b).

Elbow height from the floor, sitting. School children sat erect on an adjustable seat. The arm was pressed against the trunk. The forearm was placed horizontally, forming a right angle with the upper arm. The vertical distance from the seat to the olecranon of the right hand was measured. The measured value was then added with popliteal height of the same school children to get the sitting elbow height from the floor (Fig. 2c).

Elbow to elbow length (writing position), sitting. Horizontal distance across the lateral surfaces of the elbows when the school children write on the desk was measured (Fig. 2d).

Bi-deltoid breadth. The maximum horizontal distance between the deltoidale on either side. It was measured during sitting condition (Fig. 2e).

Eye height from the floor, sitting. The vertical distance from the floor to the entocantion was measured during sitting on an adjustable seat (Fig. 2f).

Maximum horizontal distance between calf and thigh. The school children stand erect, head in the frankfort plane and both hands stretched anteriorly. A plumb line was hung from the maximum bulge on the anterior surface of the thigh. The horizontal distance from this vertical line to the maximum bulge on the calf muscle was measured.

\section{Results}

Mismatch between furniture dimensions and anthropometric dimensions of school children

The mean values of anthropometric dimensions of the school children of different age groups as well as physical dimensions of classroom furniture used in 


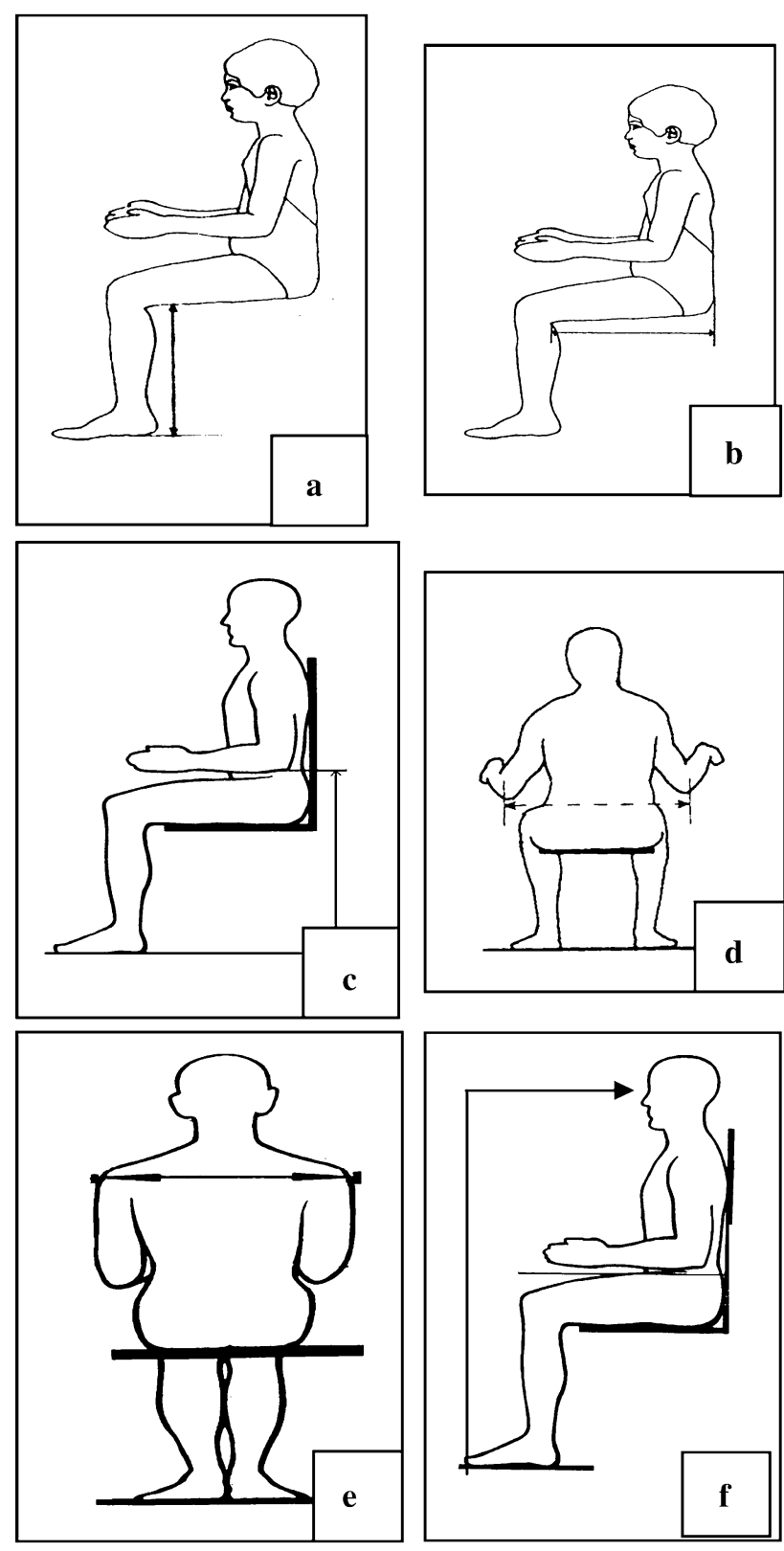

Fig. 2 Different anthropometric points in sitting posture: a politeal height, b buttock politeal length, c elbow height from the floor, d elbow to elbow height (writing position), e bideltoid breadth, $\mathbf{f}$ eye height from the floor (sitting)

different grades are presented in Table 1. The mean values of the anthropometric dimensions of the school children are found to increase gradually with increasing age. On the other hand, no remarkable changes were observed in physical dimensions of classroom furniture; that is, dimensions remained more or less the same in different grades. Remarkable percentage differences ( $>30 \%$ in many of the cases, as shown in Table 1) have been observed between the physical dimensions of the furniture and anthropometric dimensions of the school children; a greater mismatch between those measures has been noted in lower age groups.

Health complaints of the students

A high percentage (46.3-87.5\%) of the school children of different grades become fatigued (Table 2). The occurrence of neckache is high in the school children of lower age group, and it decreases as the age of the school children increases. Back problems among the school children of higher grades are more prevalent than in lower grades. Discomfort/problems of the upper limbs is prevalent among the school children (Table 2), and it decreases slightly with increasing age. The results show that the number of children suffering finger and palm problems increases with higher grades. Results show that lower arm problems are comparatively fewer than those of other locations in the body. The occurrence of shoulder joint problems gradually decreases with the children's increasing age.

Lower limb problems are prevalent among the school children (Table 2). However, the occurrence of the problem decreases with increasing age. It has been observed that a comparatively higher percentage of respondents (especially the school children of lower age groups) complains about problems in the upper leg and hip joints than in other parts of the lower limbs.

Posture change of the school children in the classroom

The number of posture changes in different parts of the body while performing classwork on school furniture shows a wide range of variations in different age groups (Table 3). The school children of middle age groups, especially 13 years old, demonstrate fewer posture changes than other age groups. The 13-year-old school children show significantly fewer $(P<0.05)$ changes in postures in all categories than the 10-year-old children and other age groups in the right and left leg and crossed legs. However, no significant difference in the frequency of posture change has been noted in most of the body parts between the school children of 10 and 11 years as well as between 13 and 14 years. With the school furniture, the school children are found to adopt a crossed-leg posture during classwork. The frequency of crossed leg posture is found to decrease with advanced age of school children; they show a significant difference $(P<0.05)$ in the number of posture changes among all pairs of age groups except for 10 and 11 years and 14 and 15 years. The school children of lower age groups adopt poor postures for a longer duration than the school children of older age groups (Table 4). The 


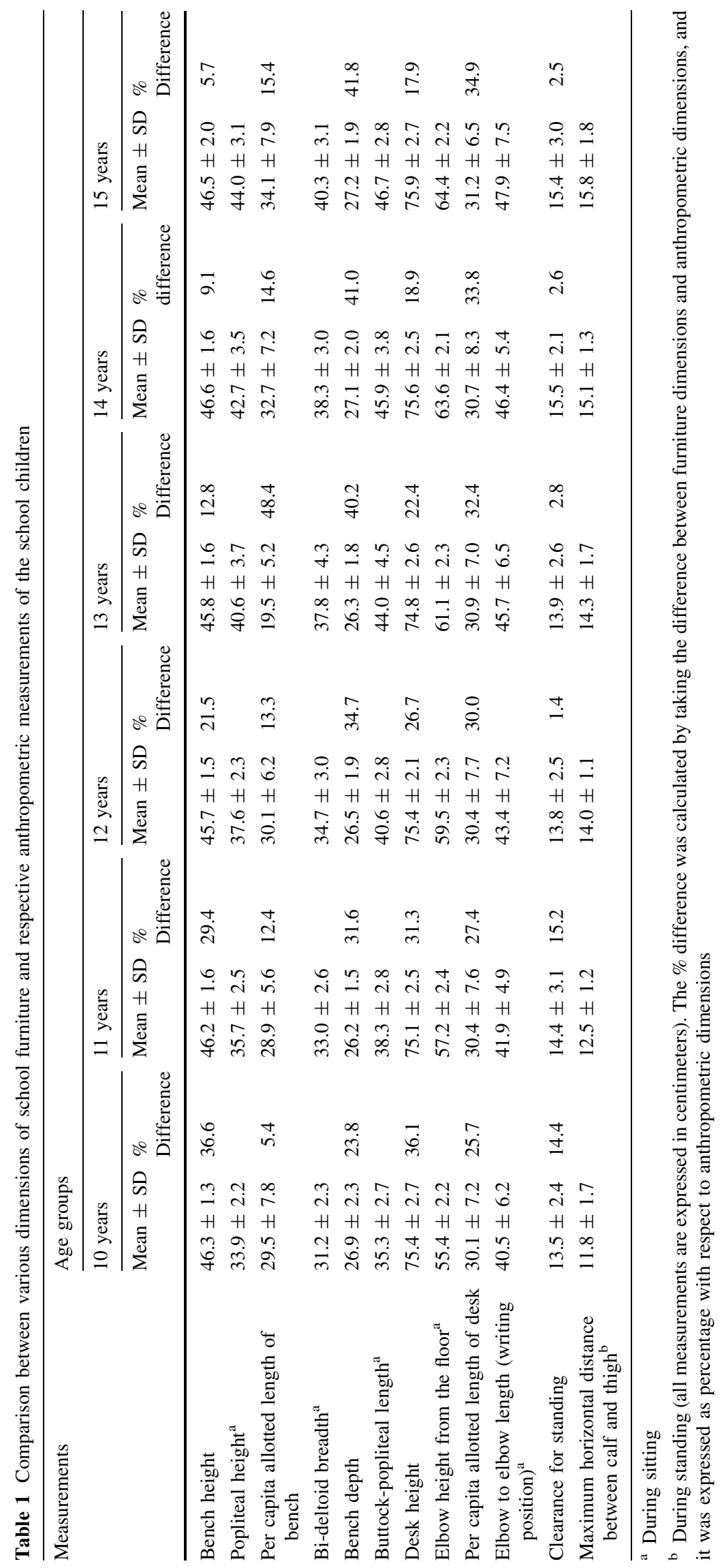


Table 2 Percentages of occurrence of discomfort/ problems among the school children during classwork ( $n=80$ in each group)

\begin{tabular}{|c|c|c|c|c|c|c|}
\hline \multirow{2}{*}{$\begin{array}{l}\text { Kinds of } \\
\text { discomfort/ } \\
\text { problem }\end{array}$} & \multicolumn{6}{|c|}{ Age groups and grades } \\
\hline & $\begin{array}{l}10 \text { years } \\
\text { (V) }\end{array}$ & $\begin{array}{l}11 \text { years } \\
\text { (VI) }\end{array}$ & $\begin{array}{l}12 \text { years } \\
\text { (VII) }\end{array}$ & $\begin{array}{l}13 \text { years } \\
\text { (VIII) }\end{array}$ & $\begin{array}{l}14 \text { years } \\
\text { (IX) }\end{array}$ & $\begin{array}{l}15 \text { years } \\
(\mathrm{X})\end{array}$ \\
\hline Fatigue & 65.0 & 62.5 & 58.8 & 46.3 & 70.0 & 87.5 \\
\hline Sleep in the classroom & 22.5 & 20.0 & 17.5 & 21.3 & 31.3 & 36.3 \\
\hline Headache & 25.0 & 30.0 & 30.0 & 23.8 & 36.3 & 35.0 \\
\hline Eye problems & 32.5 & 36.3 & 31.3 & 15.0 & 30.0 & 37.5 \\
\hline Neckache & 67.5 & 53.8 & 37.5 & 31.3 & 31.3 & 27.5 \\
\hline Backache & 25.0 & 27.5 & 31.3 & 32.5 & 42.5 & 52.5 \\
\hline Problems of upper limbs & 66.3 & 63.8 & 62.6 & 62.5 & 56.3 & 56.3 \\
\hline Fingers & 28.8 & 28.8 & 30.0 & 30.0 & 31.3 & 43.8 \\
\hline Palm & 3.8 & 6.3 & 7.5 & 8.8 & 13.8 & 15.0 \\
\hline Wrist joint & 26.3 & 23.8 & 12.5 & 11.3 & 27.5 & 37.5 \\
\hline Lower arm & 3.8 & 4.4 & 5.0 & 4.8 & 8.8 & 11.3 \\
\hline Elbow joint & 16.3 & 15.0 & 10.0 & 7.5 & 11.0 & 12.5 \\
\hline Upper arm & 18.8 & 17.5 & 15.0 & 15.0 & 17.0 & 18.5 \\
\hline Shoulder joint & 28.8 & 25.0 & 15.0 & 13.8 & 12.5 & 11.3 \\
\hline Problems of lower limbs & 67.5 & 53.8 & 52.5 & 50.0 & 43.8 & 40.0 \\
\hline Feet & 8.8 & 7.5 & 7.5 & 5.0 & 2.5 & 2.5 \\
\hline Ankle joint & 18.8 & 15.0 & 13.8 & 12.5 & 8.8 & 7.5 \\
\hline Lower leg & 11.3 & 10.0 & 8.8 & 7.5 & 7.5 & 5.0 \\
\hline Knee joint & 20.0 & 17.5 & 15.0 & 10.0 & 8.8 & 7.5 \\
\hline Upper leg & 25.0 & 22.5 & 21.3 & 17.5 & 15.0 & 12.5 \\
\hline Hip joint & 28.8 & 28.8 & 27.5 & 26.3 & 18.8 & 15.0 \\
\hline
\end{tabular}

percentage of time sitting with poor posture, in the majority of cases, is lower in the school children of middle age groups than of lower and higher age groups.

\section{Discussion}

The results of the present study show that the school furniture is far from compatible with the anthropometric measurements of school children. This furniture is designed by local carpenters without due consideration of the body dimension requirements of the school children, which may be due to their ignorance. The studies of different researchers showed that there was a significant difference between the desk height and the sum of elbow rest height and popliteal height of the school children [1]. The mismatch between the body dimensions of the school children and the school furniture has also been studied by others [9]. Such mismatch may induce physical problems in those using the furniture.

School children usually attend class for a long period of time (about $5 \mathrm{~h}$ /day) in a sitting posture with illdesigned classroom furniture. Incompatible furniture forced the school children to do classwork in unnatural postures (lateral bend, forward bend, twisting, etc.) for long periods, which imposes physical and mental strain on the children. Fatigue may be caused by sitting for long periods of time in the classroom, low nutrient levels in the body, or long duration of mental concentration. However, mismatch between furniture and body dimensions may intensify the problem of fatigue. Incorrectly designed school furniture induces improper posture, leading to operational uneasiness and musculoskeletal and some physiological disorders among school children [10]. Studies have shown that any deviation of dimensions of furniture or artifacts from the anthropometric dimensions may cause physiological and biomechanical load on the musculoskeletal system [11].

The magnitude of mismatch between desk height and elbow height becomes lower with increasing age of the school children. As the desk height is too high for the lower grade school children, they are required to raise their shoulders during deskwork, which leads to the development of neckache and problems in the upper limbs. For the upper grade school children, the desk height becomes less high with respect to their elbow 


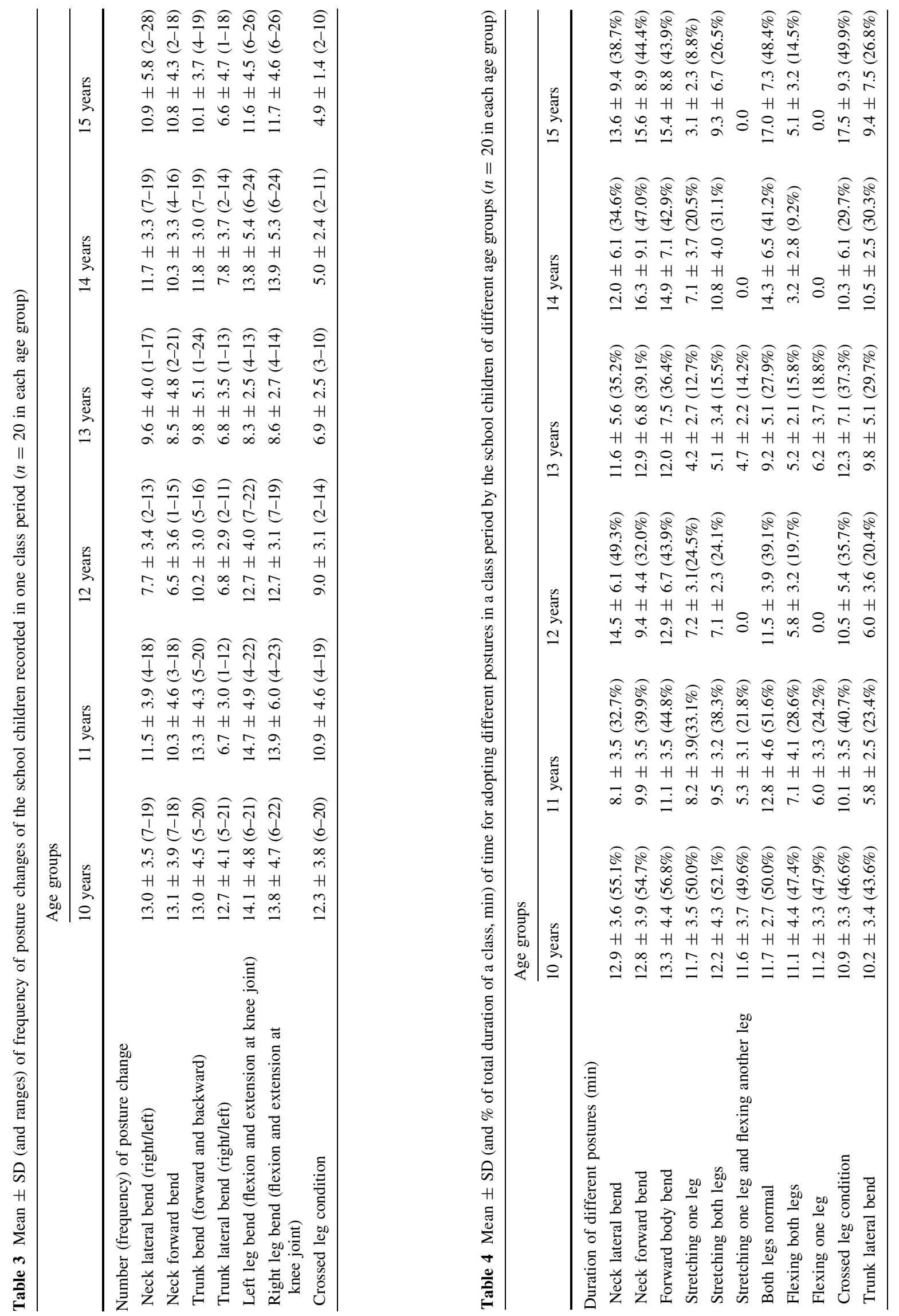


height, and therefore, the problems of neckache and upper limb discomfort are less prevalent. If the desk is raised too high, the shoulders must frequently be lifted up to compensate, which may lead to painful cramps in the neck and shoulders. Moreover, flat-type desktop surfaces in most cases cause a forward bend of the head of the school children. As an outcome, localized muscle fatigue/ pain in the neck area occurs [12].

The slanted distance between the desk surface and the eyes of the school children increases with advancing age (Table 1), as their eye height increases and the desk height remains more or less the same. Therefore, the school children of higher grades have to be bowed to maintain an appropriate reading distance. Thus, adopting a stooping posture for a long time leads to the development of lower back pain. This may be the cause for more prevalent back problems among the school children of higher grades than of lower grades. In addition, there is no backrest for the seats. This may intensify the problem of backache.

The increased number of boys suffering finger and palm problems in the higher grade may be due to more writing and drawing work than for boys of the lower grade. Inadequate space on the desk and inappropriate desk surface height may cause frequent ventriflexion or dorsiflexion and twisted movement at the wrist joint, which may be another reason for the high incidence of wrist problems.

Problems with the lower limbs may be due to the lack of compatibility between the bench height and the popliteal height of the school children. Due to high bench height and the absence of a footrest, the school children of lower age groups are compelled to sit on the front edge of the benches, hanging their legs for a long time. A seat that is too high compresses the soft tissues of the underside of the thigh [12], creating pressure that interferes with the return of blood from the lower limbs. It may cause discomfort/ problems in their thighs, knees, and feet [13].

The depth of benches in most of the rural schools is much less than the buttock-politeal length, particularly for the higher age groups. A portion of the thigh of the school children remains unsupported for a long period of time, which may cause discomfort/problems in their upper legs and hip joints. Sometimes sharp edges of the bench intensify the problem [12].
The mismatches of body dimensions and furniture dimensions may lead to quick changes of posture because of the imbalance and/or discomfort of the children's bodies while using the classroom furniture. To achieve temporary relief from these discomforts, they frequently change their sitting positions during class. They are also compelled to sit in various inappropriate postures. The greater the mismatch, the greater the frequency of posture change will be. Variations in the frequencies of posture changes in different age groups may be due to the variations in the degree of such mismatches.

Crossed-leg posture is adopted to combat instability. If the seat height is too high, the legs hang and the body becomes unstable. Crossing the legs tends to lock the joints and thus stabilize various parts of the body, although pressure on the ischial tuberosities becomes unequally distributed and can lead to discomfort [6]. When the degree of mismatch between the popliteal height of the school children and bench height decreases, the frequency of crossed leg posture also decreases, as observed for the school children of the higher age group (Table 3). Similarly, when the extent of mismatch between elbow height and the desk height decreases, the duration of adopting a forward bend posture is also lessened, as in the case of the upper age groups (Table 4).

In conclusion, health complaints may arise because of the incompatibility of the interface between the body of the school child and the school furniture. Appropriate design of classroom furniture with consideration of the body dimensions of school children and other ergonomic factors may be helpful for reducing health complaints and improving the posture of the school children in the classroom.

Acknowledgments The authors thank the school authorities who extended their active cooperation during the course of the study. The work was partly financed by the Vidyasagar University from its PRG fund.

\section{Appendix}

Questionnaire used for evaluating health complaints of the school children 
Serial no.

Date

Name and address of the school:

\section{Name of the student:}

\section{Age: Roll No: Grade:}

* Please put $(\square)$ mark in the appropriate place for your answer:

1) Do you feel fatigue during class work?

2) Do you feel any problem in your body during performing class work?

Yes/No

(i) If yes, name the part(s) of your body which is affected most:

(ii) State the type(s) of problem:

3. Do you feel any problem in your eyes during class work?

Yes/No

If yes, state the type(s) of problem:

4. Do you feel any problem in your upper limb during attending the class? Yes/No

If yes,

(i) State the name of the part (s) of the upper limb being affected:
(a) Fingers
(b) Palm
(c) Wrist joint
(d) Lower arm
(e) Elbow joint
(f) Upper arm
(g) Shoulder joint

(ii) State the type(s) of problem:

5. Do you feel backache during attending the class?

6. Do you feel neckache during performing the class work?

$\mathrm{Yes} / \mathrm{No}$

7. Do you feel any problem in your lower limb during attending the class? Yes/No If yes,

(i) State the part(s) of the lower limb being affected:
(a) Feet
(b) Ankle joint
(c) Lower leg
(d) Knee joint
(e) Thigh
(f) Hip joint

(ii) State the type(s) of problem:

8. Do you feel headache during attending the class?

Yes/No

9. Do you feel dozy in the classroom?

$\mathrm{Yes} / \mathrm{No}$

10. Have you suffered from any injury/accident in the classroom?

Yes/No

11. Do you feel any problem other than stated above?

Yes/No

If yes,

(i) State the type(s) of problem: 


\section{References}

1. Savanur CS, Ghosh S, Dhar U, De A. An Ergonomic study of comparison between school classroom furniture and student's anthropometry. In: Proceedings of the National Conference on Humanizing Work and the Work Environment, Mumbai: National Institute of Industrial Engineering, 22-24 April; 2004. p. 41-8.

2. Chakrabarti D, Das A. Design development of a new seat-desk unit suitable for Indian school children. In: Proceedings of the National Conference on Humanizing Work and the Work Environment, 22-24 April. Mumbai: National Institute of Industrial Engineering; 2004. p. 131-6.

3. Marschall M, Harrington AC, Steele JR. Effect of workstation design on sitting posture in young children. Ergonomics. 1995;38:1932-40.

4. Roebuck JA, Kroemer HE, Thomson WG. Engineering anthropometry methods. New York: Wiley-Interscience; 1975.

5. Chakrabarti D. Indian anthropometric dimensions for ergonomic design practice. Ahmadabad: National Institute of Design; 1997.

6. Galer IAR. Applied ergonomics handbook. London: Butterworths; 1987.
7. Singh IP, Bhasin MK. Anthropmetry. New Delhi: Bharathi Bhavan; 1968.

8. Weiner JS, Lourie JA. Human biology: a guide to field methods, IBP Hand Book No.9. Oxford: Blackwell; 1969.

9. Parcells C, Stommel M, Hubbard RP. Mismatch of classroom furniture and student body dimensions-empirical findings and health implications. Journal of Adolescent Health. 1999;24:265-73.

10. Chaudhary N, Sharma D, Grover R, Nainwal U. Mismatch between classroom furniture dimensions and student anthropometric characteristics: a study of schools of Pantnagar. In: Proceedings of national conference on humanizing work and work environment, 22-24 April. Mumbai: National Institute of Industrial Engineering; 2004. p. 167-71.

11. Wells R. Task analysis. In: Renney. A, editors. Chronic musculoskeletal injuries in the workplace, Philadelphia: W. B. Saunders; 1997. p. 49.

12. Kroemer KHE, Grandjean E. Fitting the task to the human: a textbook of occupational ergonomics. London: Taylor \& Francis; 2001.

13. Mandal AC. Evaluation of working position of school children. Talkback Magazine, January. UK: National Back Pain Association; 1993. 